\title{
Correction: Tracing salinization processes in coastal aquifers using an isotopic and geochemical approach: comparative studies in western Morocco and southwest Portugal
}

\author{
Paula M. Carreira ${ }^{1} \cdot$ Mohamed Bahir $^{2} \cdot$ Ouhamdouch Salah $^{2} \cdot$ Paula Galego Fernandes $^{3} \cdot$ Dina Nunes $^{1}$ \\ Published online: 23 July 2018 \\ (C) Springer-Verlag GmbH Germany, part of Springer Nature 2018
}

Correction to: Hydrogeology Journal (2018)

https://doi.org/10.1007/s10040-018-1815-1

\section{Editor's Note:}

The country map in Fig. 1a was published following the policy of Hydrogeology Journal to display country names and borders, in accordance with United Nations guidance: http:// www.un.org/Depts/Cartographic/map/profile/morocco.pdf

Hydrogeology Journal's policy is neutral regarding jurisdictional claims in published maps and institutional affiliations. Following publication, the authors expressed a preference to display a different representation of the region; however, figures cannot be replaced in published articles.

This article is part of the topical collection "Coastal aquifers in the Middle East and North Africa region"

The online version of the original article can be found at https://doi.org/ 10.1007/s10040-018-1815-1

Paula M. Carreira

carreira@ctn.tecnico.ulisboa.pt

Mohamed Bahir

bahir@uca.ma

Paula Galego Fernandes

ppfernandes@ciencias.ulisboa.pt

1 Centro de Ciências e Tecnologias Nucleares (C2TN), Instituto Superior Técnico, Universidade de Lisboa, Estrada Nacional $N^{\circ} 10$, ao km 139,7, 2695-066 Bobadela LRS, Portugal

2 Ecole Normale Supérieure, Cadi Ayyad University, Marrakesh, Morocco

3 Instituto D. Luiz, Campus Universitário, Campo Grande, Lisboa, Portugal
Thus, this Correction modifies the Fig. 1a caption to read as follows:

Fig. 1 a Essaouira regional map with the groundwater sample locations (W Morocco). [Following the Hydrogeology Journal policy, this map conforms to the published guidance of the United Nations (http://www.un.org/Depts/Cartographic/map/ profile/morocco.pdf) and does not represent the jurisdictional convictions and opinions of the authors]. The orange circles represent the sampled Turonian aquifer points; the pink circles represent the Plio-Quaternary sampled points. b-c Schematic cross sections of Essaouira sedimentary basin. 